\title{
THE JOURNAL OF PERIODONTOLOGY
}

\author{
April, Nineteen Hundred Fifty-One
}

\section{Experimental Periodontal Reattachment in Rhesus Monkeys*}

\author{
By Sigurd RamfJord, L.D.s., M.s., PH.D. Ann Arbor, Micbigan
}

$\mathrm{R}^{\mathrm{E}}$ EATTACHMENT, in periodontal terminology, means a unification or an attachment between the tooth and the adjacent soft tissue wall of the periodontal pocket. It has, for years, been one of the most controversial and extensively debated subjects in the periodontal literature. ${ }^{8,10,26,31,32}$ An attachment of the surrounding soft tissues to the tooth, following treatment of the periodontal pocket, has clinically been obtained by. a number of outstanding periodontists and teachers of pericdontia. ${ }^{2,4,5,6 . \tau, 13,14,15,18,19,25,29,35,36,37,40}$ The convincing histological proof, however, has been missing for the obvious reason that the fortunate patients on whose teeth the healing has been obtained did not want to sacrifice their teeth for microscopic examination.

Two experimental attempts on reattachment in rhesus monkeys have been reported. One was reported by Stone ${ }^{38}$ who surgically created periodontal pockets and left them alone. He obtained some healing in the bottom part of the pockets. Similar experiments with surgically made pockets and some ensuing healing have been reported both in other animals and in man. ${ }^{3,6,12,27,34}$

Fish $^{16}$ reported another experiment with surgically made pockets in rhesus monkeys. He obtained only some degree of healing, or what he called reattachment, in cases where the gum margins were healthy, but he did not obtain any reattachment where a gingivitis existed. When the gingiva was inflamed, the epithelium simply grew down to the point where the periodontal fibers were still normally attached to the uninjured cementum.

\section{OWN INVESTIGATION}

The first purpose of this experimental work was to investigate the possibility of reattachment in inflamed epithelialized periodontal pockets in rhesus monkeys by using a therapy which has proved to give clinical reattachment in man. ${ }^{2,14,15}$ The second and most important object of the investigation was to study the nature of the reattachment if any was achieved.

The experiments were performed on four healthy rhesus monkeys from four to six years old. A gingivitis, ranging in degree from mild to severe, was present around the teeth that were included in the experiment, but no periodontal pockets were present. Kodachrome pictures were taken (Fig. 1). The distances

\footnotetext{
*From the Dental School, University of Michigan, Department of Oral Pathology and Periodontia.

*This is a portion of the material from a thesis submitted in partial fulfillment of the requirements for a Ph.D. degree.
} 


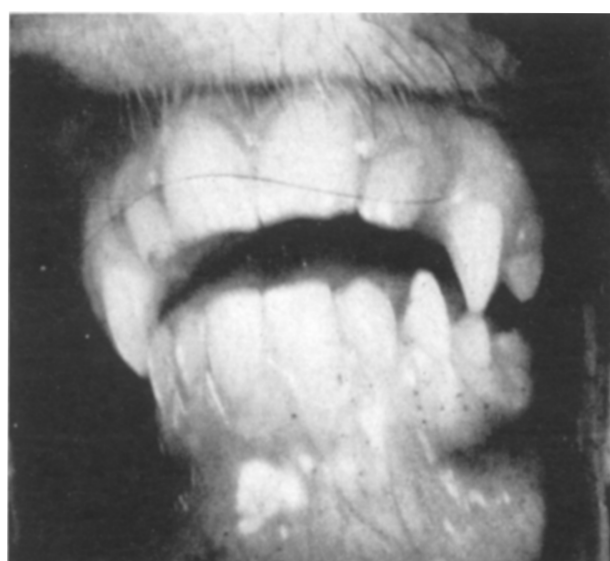

Fig. 1. Monkey \#1868 before the experiment.

from the incisal corners of the incisor teeth to the bottom of the interproximal gingival crevices were measured with a thin silver point of the type which is used for root canal fillings. These teeth had sharp, welldefined mesial and distal incisal corners, to provide definitely fixed points on the teeth from which the height of the interproximal epithelial attachment and later the decrease in depth of the pockets could be measured. In many previous publications on reattachment the depth of the pockets has been measured from the free gingival margin which is continually changing in height during the treatment. This has resulted in a false interpretation of experimental data. When mesial or distal measurements are given in this paper without further designation, they always refer to the distances from the mesial or distal incisal corners to the bottom of the interproximal crevices. The monkeys were anesthetized by nembutal (pentobarbital sodium), and deep interproximal pockets extending below the alveolar crest margin were created. The periodontal membrane is rather thin in monkeys, so some alveolar bone had to be removed in order to obtain pockets of sufficient width and depth, and in most cases some tooth substance also was removed at the bottom of the created pocket for futher reference. Copper bands were adapted to the experimental teeth and extended down to the bottom of the surgically created pockets

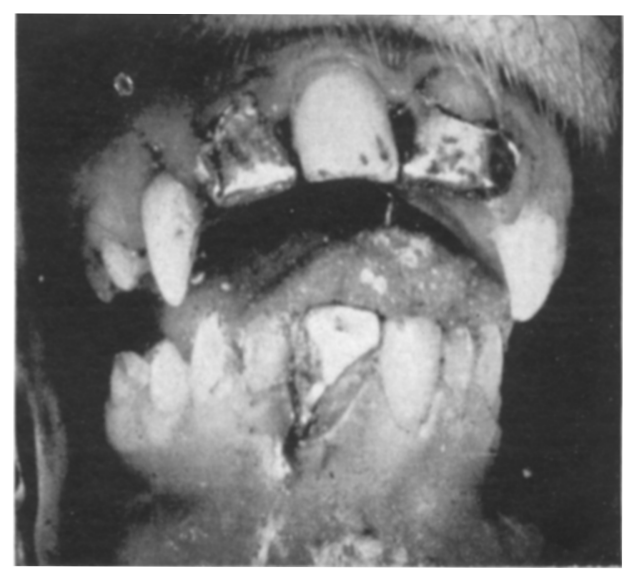

Fig. 2. Monkey \#1868, the copper bands in place.

(Fig. 2). A similar method has been described by Swenson. ${ }^{39} \mathrm{He}$ adapted and polished the bands as close to the roots as possible to minimize the irritation, but in this experiment a severe inflammation was desired, so the bands were cemented on the teeth without being closely adapted. Occlusal interference was avoided, but nothing was done to eliminate the interproximal trauma which occurred from forcing the band through the tight interproximal contacts. The interproximal measurements of the bands were recorded. In a few cases the bands did not extend quite to the bottom of the surgically created pockets, as may be seen in Table I. Swenson, in his experiment on dogs, removed the copper bands after fifteen days. Tissue sections at that time showed inflammation and downgrow th of epithelium on the gingival wall to the bottom of the pocket. The dogs were sacrificed 150 days after the bands were removed, and histologic sections showed a pocket very similar to the pathologic periodontal pocket occurring in man. He examined one hundred pockets of this type and stated that no reattachment occurred after the bands were removed. According to his findings, this type of copper band, cemented on the teeth for fifteen days in dogs with a healthy gingiva, invariably created permanent periodontal pockets. Fish $^{16}$ observed in monkeys that if a gingivitis was present before the surgical 


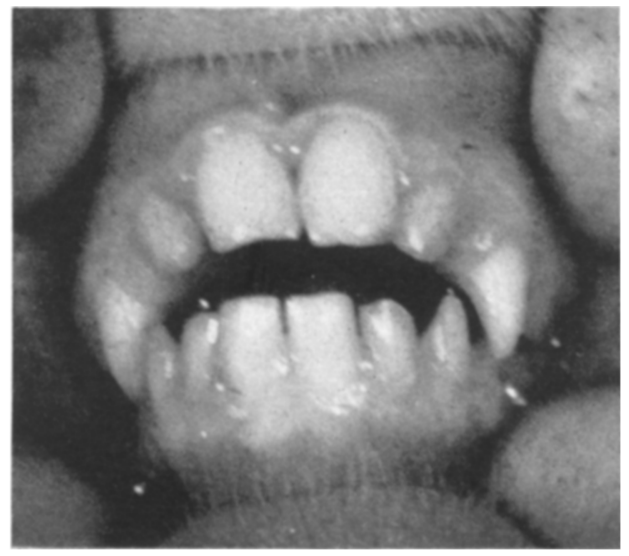

Fig. 3. Monkey \#1868. At the time of death.

pocket was made, the inflammation from the gingivitis alone would prevent any reattachment.

A severe acute gingival inflammation developed shortly after the bands were cemented, but the appearance gradually changed to resemble very closely the clinical picture of a periodontitis caused by a gold crown with overhanging margins. It was decided to leave the bands on the teeth for as long as twenty-six to thirty-one days in order to assure time enough for the epithelium to grow down the gingival wall to the bottom of the pocket, and for the inflammation to assume more of the chronic character seen in periodontitis. The irritation from the bands and the destruction of transeptal fibers caused pockets to develop on the adjacent teeth, so in the cases in which only one interproximal pocket was made on a tooth, a pocket developed gradually, both on the adjacent tooth and on the opposite interproximal side on the same tooth. These pockets were not surgically created, but pockets developed as a sequence of inflammation. This proves what has been assumed from clinical evidence that irritation and inflammation may lead to pocket formation. Five of the deepest pockets of this type are included in the report. Kodachrome pictures were taken when the bands were removed, and the distances from the incisal corners to the bottom of the pockets were recorded. The teeth were scaled lightly and the pockets were washed with a mild iodine lotion. This treatment was repeated after two and after seven days. Ten days after the bands were removed the inflammation had subsided somewhat, but with the poor oral hygiene and the accumulation of food debris and materia alba on the teeth and in the pockets, an active inflammation with some accumulation of pus persisted. No changes in the depth of the pockets could be observed. The roots were thoroughly scaled and filed as smooth as possible. Thereafter, the pockets, both artificially made pockets and pockets gradually developed from local inflammation, were packed with cotton strings that

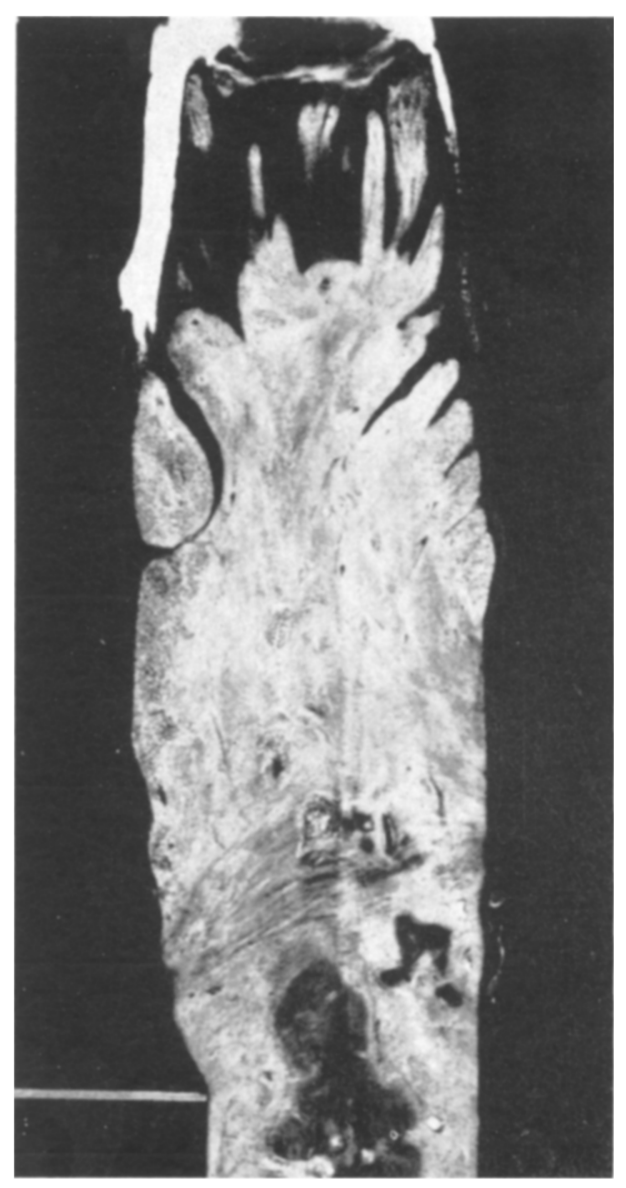

Fig. 4. Monkey \#1899, tooth \#8 distal. Clinially $3 \mathrm{~mm}$. decrease in pocket depth following treatment. The white line indicates the depth of tion of the copper band. 
had been saturated in a mixture of $75 \%$ phenol and $25 \%$ camphor. The packs were removed after five minutes and the pockets flushed with warm water and later dried with cotton rolls and hot air. An attempt was made to scrape away the cauterized epithelial lining and to get blood to fill tha pocket. The area was kept dry for about ten minutes to allow the blood to clot within the pocket before it was exposed to the saliva. The teeth were later scaled and polished twice a week until the monkeys were sacrificed. The phenol-camphor pack treatment was repeated one month later. The first scalings after this type of treatment have to be performed with great care because the developing attachment is easily destroyed at that early stage. Materia alba accumulates very fast on the teeth of the monkeys and the clinical results were not as good as the results obtained in cooperative patients. A mild gingivitis was still present in all cases at the time of death. The monkeys were sacrificed 90 to 117 days after the bands were removed. Kodachrome pictures (Fig. 3) and dental $\mathrm{x}$-rays were taken, clinical findings and measurements recorded, models made, and the jaws immediately fixed in Bouin's solution.

\section{CLINICAL FINDINGS}

The clinical findings are recorded in Table I. In the few instances where the bands did not extend quite down to the bottom of the surgical pockets, a healing occurred before the bands were removed, reattaching the soft tissues up to, or almost up to the edge of the band. In a few cases the measurements at the time of removal were found to be $0.5 \mathrm{~mm}$. shorter than the bands, which can be explained by the bands being situated at some small distance from the root, thus allowing a limited healing to take place in the space between the edge of the band and the root. One should also allow for a possible error of $0.5 \mathrm{~mm}$. in the clinical measurements of this type. The measurements were always taken along the root surface and could, therefore, in these cases be slightly shorter than the bands. The photomicrographs shown in this article are all from cases in which no healing had occurred before the periodontal treatment with removal of the epithelial lining had been performed. The clinical reattachment is equivalent to the difference in measurements from when the bands were removed to when the monkeys were sacrificed. Reattachment measuring from one to four $\mathrm{mm}$. was obtained in all but one of the eighteen pockets which were treated.

In a few additional instances pockets were created surgically and left alone. Two such cases are included in Table I. They showed complete healing which is in accordance with previously mentioned reports.

\section{MICROSCOPIC FINDINGS AND INTERPRETATIONS}

In most cases it was possible from healed surface injuries on the root to identify $\mathrm{mi}$ croscopically the original depth of the surgically created pockets (Fig. 4). Fragments of cementum and dentin were incorporated batween the periodontal fibers, and new cementum appeared to be deposited on these displaced parts of the root (Fig. Sb). The zone of reattachment, from the bottom of the created pocket to the bottom of the gingival sulcus, showed both attachment of connective tissue fibers associated with formation of new cementum and epithelial attachment on old cementum or dentin surfaces $^{1,11}$ (Fig. 6a). Evidence of resorption and subsequent healing was of ten observed on the previously denuded root surfaces (Figs. 6b and 6c). Alternating zones of connective tissue and epithelial attachment were observed in some cases (Figs. $7 \mathrm{a}$ and 7b). From correlating clinical and histological data it was evident that both connective tissue and epithelial reattachment had occurred on root surfaces which had been, first, covered by bands and later exposed in chronically inflamed periodontal pockets (Fig. 5a). New bone formation was of ten noted on the alveolar crest (See Figs. Sa and $6 a)$. The new connective tissue attachment to the root was always associated with 


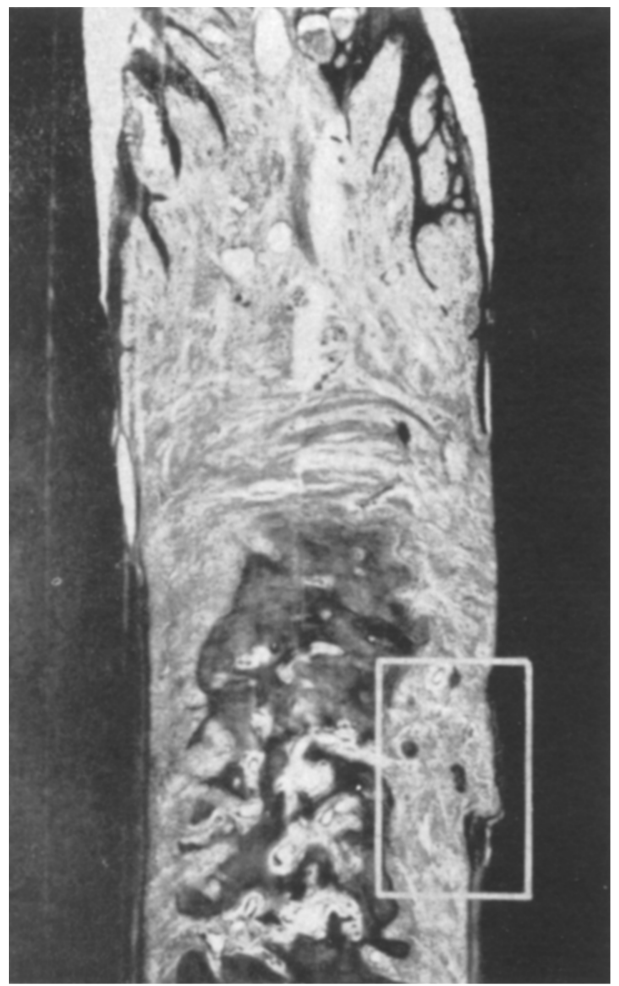

Fig. ธேа.

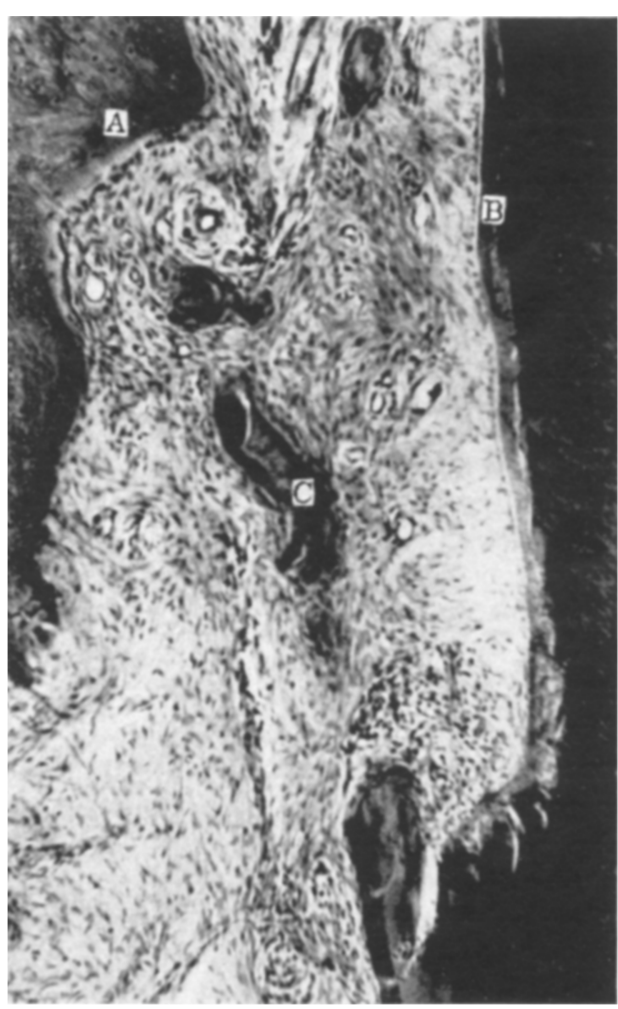

Fig. 5 b.

Figs. 5a and 5b are from Monkey \# $\mathrm{T} 28$, tooth \#10 mesial. Clinical decrease in the depth of the pocket $3.5 \mathrm{~mm}$. during treatment. leposition of bone on the alveolar lamina (A). Cementoblastic activity on the root $(\mathrm{B})$ and on the surface of dislodged fragments of the tooth $(\mathrm{C})$

cementoblastic activity (Figs. $8 \mathrm{a}$ and $8 \mathrm{~b}$ ), and in some places a rather thick layer of new formed cementum was observed.

The new epithelial attachment resembled the normal epithelial attachment, the nature of which is not known in detail. ${ }^{9,30}$ The epithelial reattachment of ten consisted of only a few layers of flat almost spindleshaped cells (Fig. 9), in other places the epithelium was growing out in deep pegs. Numerous nests and strands of epithelium were seen in the area of healing, extending deep in the connective tissue. They were possibly remains of epithelial pegs from the time that the epithelial covering of the pocket was cauterized and scraped away (See Fig. 7b). A zone of concentrated accumulation of inflammatory cells, mainly plasma cells, but also some lymphocytes and mononuclear histiocytes, were often seen adjacent to the epithelial reattachment (Fig. 10). Infiltrations of inflammatory cells were occasionally observed between the fiber bundles of the reattached connective tissue, extending down to the bottom of the previous pocket (Fig. Sb). A mild gingivitis was present in all of the cases that had been treated.

No reattachment occurred from the time the bands were removed until the epithelial lining of the pocket was cauterized and scraped away. In the one case that didn't show any diminishing of pocket depth during the period of treatment (Fig. 11), a very marked inflammation was persisting to the time of death of the animal. The pocket was narrow and the treatment had obviously not extended to the bottom of the pocket. The degree of organization of the blood clot in the pocket was probably 


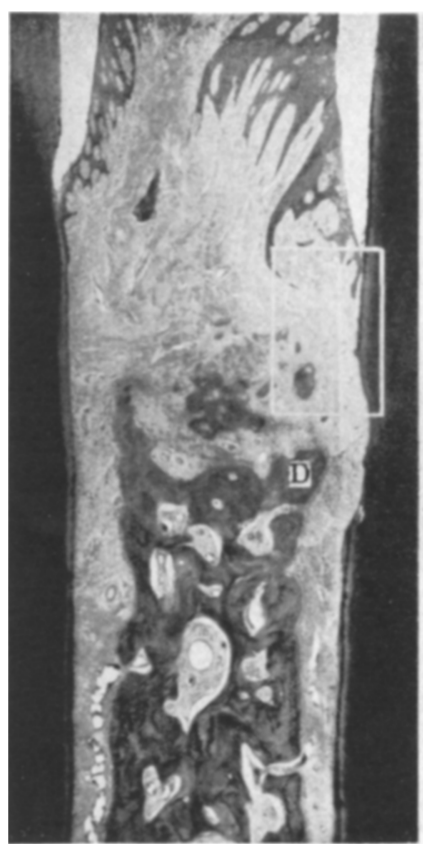

Fig. 6a.

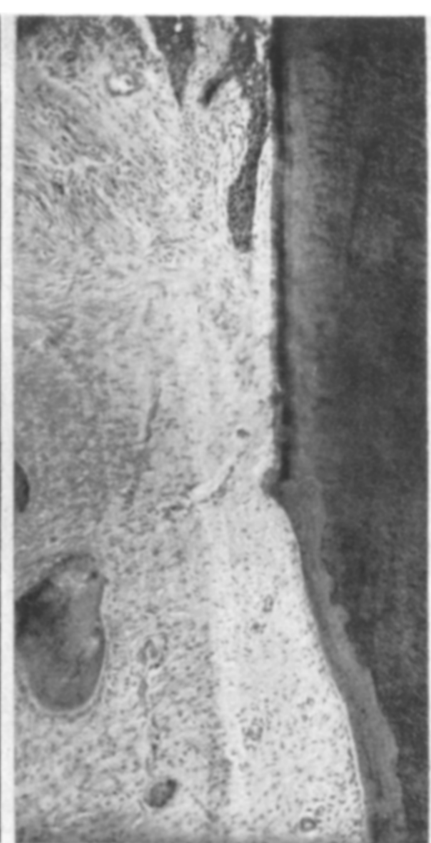

Fig. 6b. $(\mathrm{x} 105)$

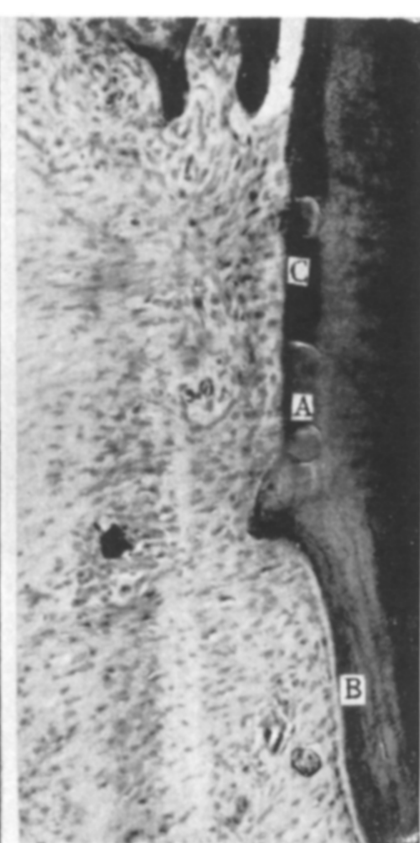

Fig. 6c. $(\times 320)$

Figs. 6a, 6b, and 6e are from monkey \#1899, tooth \#24 mesial. Clinically the depth of the pocket decreased $2 \mathrm{~mm}$. during treatment. Resorption and repair of old cementum (A). New formation of cementum both on the previously denuded dentin (B) and on the surface of the old cementum
(C). New bone formation reestablishing the normal width of the periodontal membrane (I)).

dependent upon the amount of irritation and inflammation which was residual following phenol-camphor treatment. The cauterization and the removal of the epithelial surface will produce an inflammatory reaction, and the organizing blood clot will be effected by local irritation, but it was believed that the state of the underlying tissue before the attempt on reattachment was the most important factor, this also conforms with the repeated statement in the literature that reattachment should only be attempted when the local inflammation has subsided. Epithelium from the free gingival margin starts to cover the organizing blood clot, and when the proliferating basal layer of the epithelium reaches the position in which the granulation tissue contacts the tooth, it grows down along the root surface, attaching itself to the tooth until its downgrowth is stopped by connective tissue fibers attached to the root surface by new formed cementum. This process is similar to the downgrowth of the epithelial attachment which occurs both during the physiological eruption and pathological pocket formation. It is no reattachment of old epithelium, but new growing epithelium in which tonofibrils utilize the microscopic roughness on the tooth surface for attachment.

It is frequently stated in the periodontal literature that the position of the epithelial attachment is determined by the presence of periodontal fibers, and that following a destruction of fibers the epithelial attachment will grow down until it reaches attached fibers. ${ }^{17}, 20,21,23,24,33$ It appeared as if the reattachment of the epithelium followed the same pattern as the normal epithelial attachment. A fibrous organization of the granulation tissue in the area of repair and cementoblastic activity appeared to be dependent upon the severity of 


\section{Page 74}

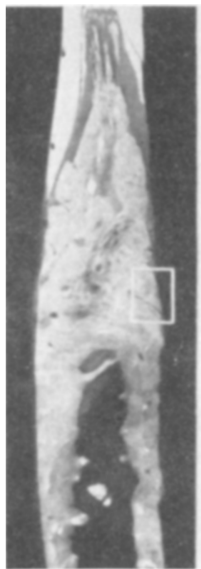

Fig. 7a.

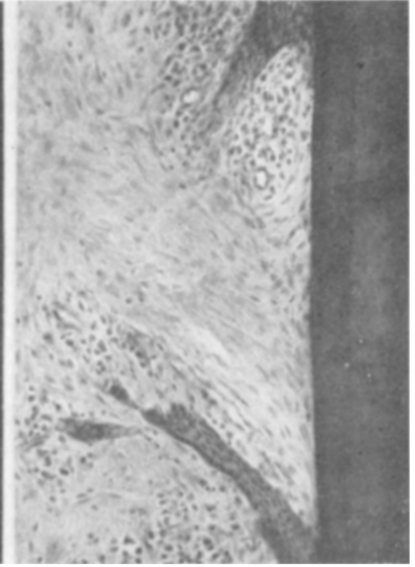

irig. 7b. $(\times 320)$

Figs. 7a and 7b are from monliey \#1887. tooth \#24 distal. Alternating zones of connective tis sue and epithelial reattachment. Inflammator intiltrations, chiefly plasma cells.

the inflammation present. If the granulation tissue that replaced the blood clot was pyogenic in type the environment was not conducive to cementoblastic activity nor to production of collagenous fibers, ${ }^{22,28}$ and there was nothing to prevent the epithelial attachment from growing down along the root surface until it reached the residual periodontal fibers at the bottom of the previously produced pocket. The practical application of the reported findings should be that subgingival curettage attempting reattachment of connective tissue type is only indicated where the periodontal tissues can be brought to a good state of health during the hygienic phase of the periodontal treatment.

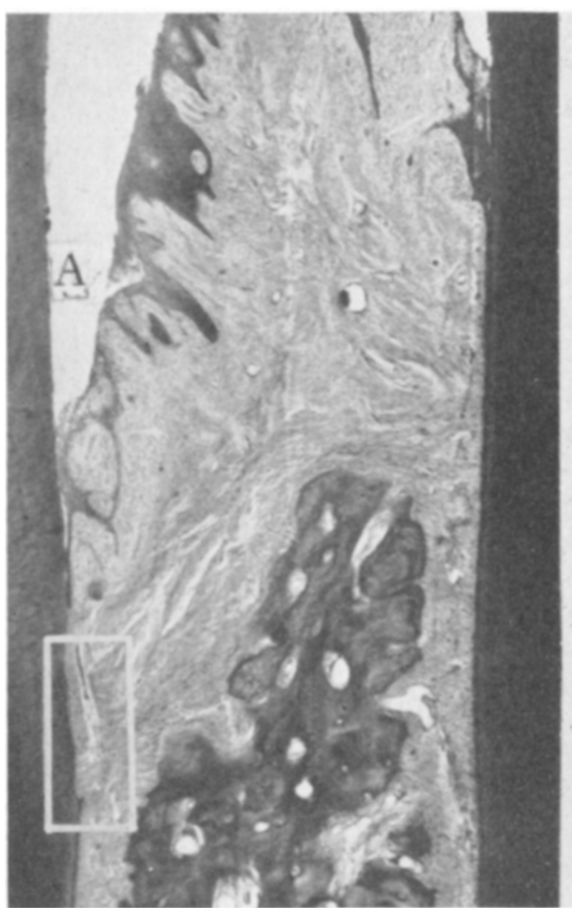

Fig. 8a.

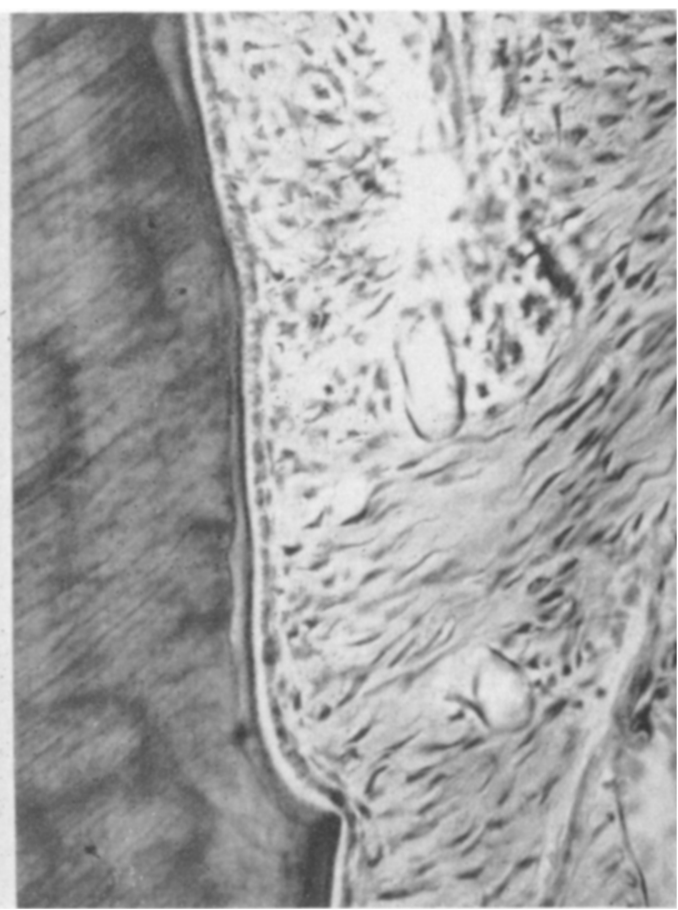

Fig. 8b. (x280)

Figs. $8 \mathrm{a}$ and $8 \mathrm{~b}$ are from Monkey \#T28, tooth \#24 mesial. Clinically $2 \mathrm{~mm}$. reattachment during treatment. Residual pocket (A). About one-half of the zone of reattachment is connective tissue reattachment. 


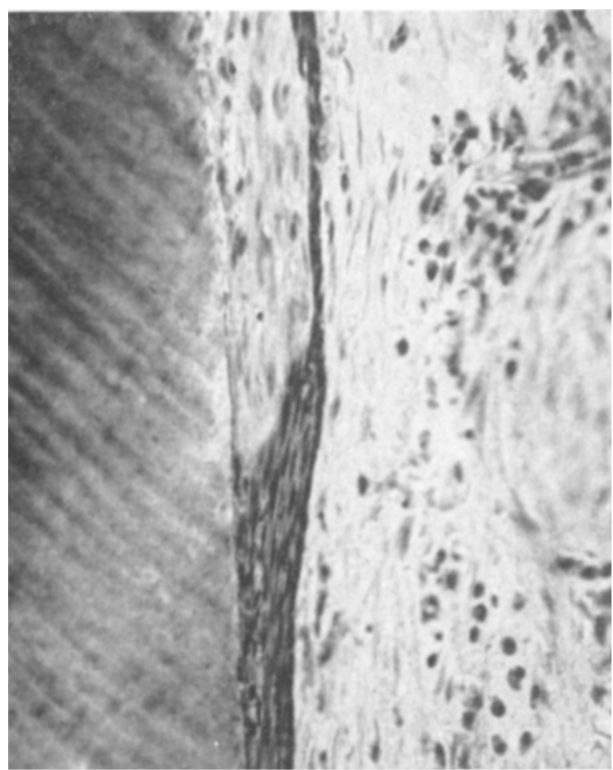

Fig. 9 (x320), Monkey $\# 1899$. Tooth $\# 10$ distal. Epithelial reattachment, spindle-shaped squamous epithelial cells on previously denuded dentill surface.

\section{CONCLUSION}

1. Both connective tissue and epithelial reattachment was observed on root surfaces that had been exposed in an inflamed periodontal pocket.

2. Removal of the epithelial lining of the periodontal pocket was necessary to obtain reattachment.

3. The degree of inflammation in the area of healing appeared to determine whether the reattachment would be epithelial or connective tissue in type. The least degree of inflammation was associated with connective tissue reattachment.

4. In one case of severe gingival inflammation no reattachment was obtained.

The author reports he is indebted to the Department of Epidemiology, School of Public Health, University of Michigan, for providing the facilities for this work, and also to Miss Edna K. Mallory, School of Dentistry, for the preparation of histological sections, and to Miss Winnifred Arnold, School of Dentistry, for photographic services.

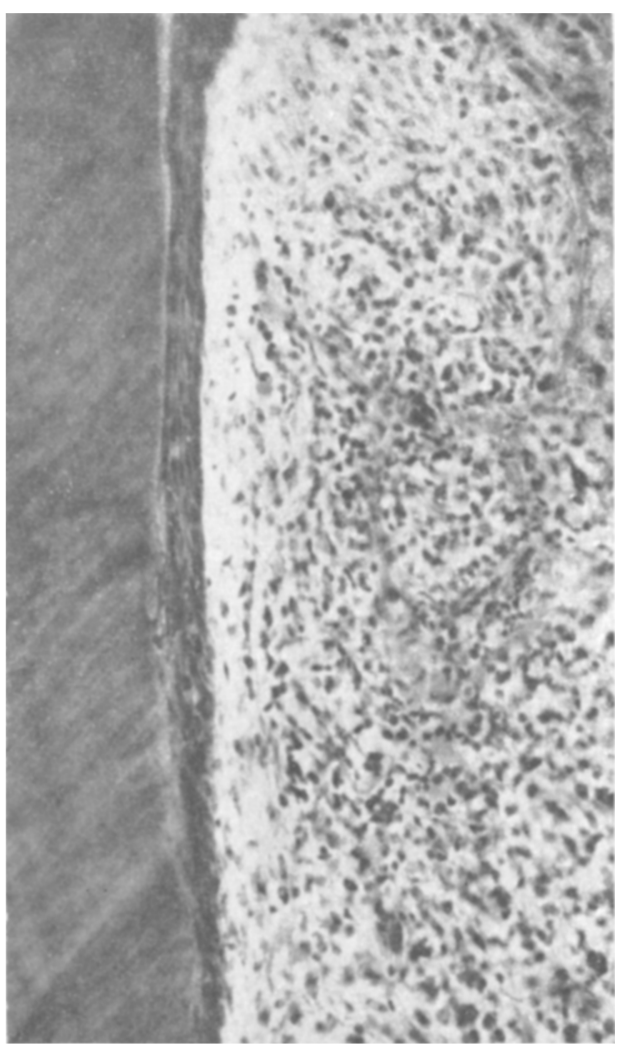

Fig. 10 (x320). IJigh magnification of Jig. 4 Epithelial reattachment in the presence of severe inflammation.

BIBLIOGRAPHY

1. Aisenberg, M. S. "Adaptability of the Periodontal Membrane," J. Dent. Res., 26:421, 1947.

2. Barkann, Lillian "A Conservative Surgical Technic for the Eradication of a Pyorrhea Pocket," J.A.D.A., 26:61, 1939.

3. Beckwith, T. D., Williams, Adrienne, and Fleming, W. C. "The Regeneration of Rodent Peridental Membrane," Soc. Exp. Biol. and Med., 24: $562,1927$.

4. Beube, F. E. "A Study on Reattachment of the Supporting Structures of the Teeth," J. of Periodont., 18:55, 1947.

5. Beube, F. E. "Interdental Tissue Resection," Amer. J. Orth. and Oral Surg., 33:497, 1947.

6. Beube, F. E., and Silvers, H. F. "Influence of Devitalized Heterogeneous Bonepowder on Regeneration of Alveolar and Max. Bone of Dogs," J. Dent. Res., 14:15, 1934. 


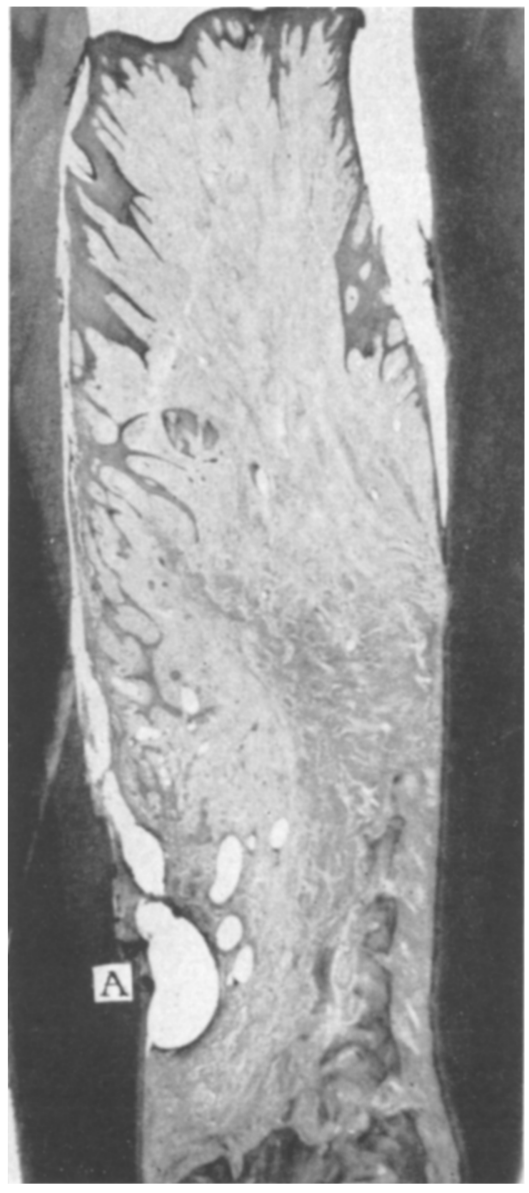

Fig. 11. Monkey \#T28, Tooth \#8 distal. Clinically no reduction in depth of the pocket. Intraalveo lar pocket extending slightly below the level of surgical detachment $(\lambda)$.

7. Bjorndahl, O. "Reattachment and Bone Regeneration; Report of a Case," J.A.D.A., 36:356, 1948.

8. Black, A. D. "Treatment of Peridental Inflammation Coordinated with Physiological Reactions of the Tissues," J.A.D.A., 24:1587, 1937.

9. Boedecker, C. F. "Histology to Operative Dentistry and Periodontia," J. Dent. Education, 4:171, 1939.

10. Boedecker, C. F. "Concerning the Reattachment of the Periodontal Membrane to Cementum," J. Dent. Education, 6:236, 1942.

11. Boedecker, C. F., and Lefkowitz, W. "Replantation of Teeth," Dent. Items of Interest, 57: 672,1935 .
12. Borden, S. M. "Histological Study of Healing Following Detachment of Tissue as is Commonly Carried Out in The Vertical Incision for the Surgical Removal of Teeth," J.C.D.A., 14:510, 1948.

13. Box, H. K. "Treatment of the Periodontal Pocket," The University of Toronto Press, 1929.

14. Bunting, R. W. "The Control and Treatment of Pyorrhea by Subgingival Surgery," J.A.D.A., 15: $119,1928$.

15. Bunting, R. W. Oral Hygiene and the Treatment of Parodontal Diseases. Philadelphia: Lea and Febiger, 1936.

16. Fish, W. E. Parodontal Disease. London: Eyre and Spottiswoode, Ltd., 1946.

17. Goldman, H. M. "The Relationship of the Epithelial Attachment to the Adjacent Fibers of the Periodontal Membrane," J. Dent. Res., 23:177, 1944.

18. Goldman, H. M. "Subgingival Curettage. A Rationale." J. Periodont., 19:54, 1948.

19. Goldman, H. M. "A Rationale for the Treatment of the Intrabony Pocket; One Method of Treatment, Subgingival Curettage," J. of Periodont., 20:83, 1949.

20. Gottlieb, B. "Tissue Changes in Pyorrhea," J.A.D.A., 14:2178, 1927.

21. Gottlieb, B. "Biology of the Cementum," $J$. Periodont., 13:13, 1942.

22. Hass, G., and McDonald, F. "Studies of Collagen. I and II," Amer. J. of Path., 16:525, 1940.

23. Häupl, K. Grundriss der Histo-Patbologie des Zabnes und seines Stützapparates. Leipzig: J. A. Barth, 1940.

24. Kronfeld, R. "A Case of Tooth Fracture, With Special Emphasis on Tissue Repair and Adaptation Following Traumatic Injury," J. Dent. Res., 15:429, 1936.

25. Leonard, H. J. "Periodontal Treatment for Maximum Reattachment," J.A.D.A., 22:602, 1935.

26. Leonard, H. J. "Periodontia Procedure," J. Periodont., 16:141, 1945.

27. Linghorne, W. J., and O'Connell, D. C. "Studies in the Regeneration and Reattachment of Supporting Structures of the Teeth," J. Dent. Res., 29:419, 1950 .

28. Maximow, A. "Development of Argyrophile and Collagenous Fibers in Tissue Cultures," Proc. Soc. Exper. Biol. and Med., 25:439, 1928.

29. McCall, J. O. "An Improved Method of Inducing Reattachment of the Gingival Tissues in Periodontoclasia," Dent. Items of Inter., 48:342, 1926. 
30. Orban, B., and Mueller, E. "The Gingival Crevice," J.A.D.A., 16:1206, 1929.

31. Orban, B. "Gingivectomy vs. Conservative Treatment of Periodontal Disease," J. South. Cal. State D. A., 15:15, 1948.

32. Orban, B. "Pocket Elimination or Reattachment?" N. Y. State Dent. J., 14:227, 1948.

33. Rushton, M. A. "The Fibre-Structures at the Gingival Attachment of Deciduous Teeth," Brit. Dent. J., 86:105, 1949.

34. Skillen, W. G., and Lundquist, G. R. "An Experimental Study of Peridental Membrane Reattachment in Healthy and Pathologic Tissues," J.A.D.A., 24:175, 1937.
35. Smith, T. S. "Constructive Treatment of Diseased Paradental Tissues," J.A.D.A., 22:1477, 1935.

36. Stewart, H. S. "Partial Removal of Cementum and Decalcification of a Tooth in the Treatment of Pyorrhea Alveolaris," Dent. Cosmos, 41:617, 1899.

37. Stillman, P. R. "The Management of Pyorrhea," Dent. Cosmos, 59:405, 1917.

38. Stones, H. H. "The Reaction and Regeneration of Cementum in Various Pathological Conditions," Proc. Roy. Soc. Med., 27:728, 1934.

39. Swenson, H. M. "Experimental Periodontal Pockets in Dogs," J. Dent. Res., 26:273, 1947.

40. Younger, W. J. "Some of the Latest Phases in Implantation and Operations," Dent. Cosmos, 35:102, 1893 . 